\title{
Assessment of Diversity in Commercial Hybrids of Pearl Millet in India
}

\author{
OP Yadav' ${ }^{1}$ KN Rai ${ }^{2}$, HP Yadav ${ }^{3}$, BS Rajpurohit ${ }^{1}$, SK Gupta ${ }^{2}$, A Rathore ${ }^{2}$ and CG Karjagi ${ }^{4}$ \\ ${ }^{1}$ ICAR-All India Coordinated Pearl Millet Improvement Project, Mandor, Jodhpur-342304, Rajasthan, India \\ ${ }^{2}$ International Crops Research Institute for the Semi-Arid Tropics, Patancheru-502324, Telanagana, India \\ ${ }^{3}$ CCS Haryana Agricultural University, Hisar-125004, Haryana, India \\ ${ }^{4}$ ICAR-Indian Institute of Maize Research, Pusa Campus, New Delhi-110012, India
}

(Received: 23 October 2015; Revised: 10 February 2016; Accepted: 15 February 2016)

\begin{abstract}
Availability of diverse cultivars is essential in order to meet necessity of regional adaptation to various climatic conditions and to fulfil the farmers' need of differential preference of various phenotypic traits in pearl millet. The present study attempted to quantify the degree of diversity in commercial hybrids of pearl millet and to understand the relationship among various phenotypic and quality traits. A total of 122 commercial hybrids were evaluated at three diverse locations. Results showed large variation for flowering time (42-58 days), tillering (1.1-4.4 panicles/plant), individual grain size $(7.6-17.3 \mathrm{mg})$, plant height $(185-268 \mathrm{~cm})$, panicle length $(20-33$ $\mathrm{cm})$ and grain yield (35-72 q/ha). Clustering of hybrids resulted in 7 distinct clusters, which highlighted the successful efforts of national programme of pearl millet improvement toward genetic diversification of hybrids. These results are discussed as to how this reported diversity has helped in extending the hybrid technology in some of the most difficult and diverse production ecologies. Phenology, tillering and height had significant influence on yields of hybrids. Taller hybrids provided higher yield. Hybrids with lesser duration and shorter height produced more tillers and tillering decreased with the increase in panicle length. The correlation of grain yield with $\mathrm{Fe}$ and $\mathrm{Zn}$ concentration in grains was not significant suggesting that both these micronutrients can be improved without significantly compromising on grain yield.
\end{abstract}

\section{Key Words: Adaptation, Genetic diversity, Hybrids, Pearl millet, Trait association}

\section{Introduction}

Pearl millet (Pennisetum glaucum L. R. Br.) is the most important dryland cereal in arid and drier semi-arid tropics. It is an essential component of staple food in parts of India and sub-Sahara Africa and its dry stover is significant component of ration to a large number of bovine livestocks especially during dry periods of year. Its nutritious grains contain higher iron $(\mathrm{Fe})$ and zinc (Zn) than rice, wheat and maize (Rai et al., 2008). There is also increasing utilization of pearl millet grain in nonfood uses like feed and alcohol extraction (Basavaraj et al., 2010).

Pearl millet is grown in diverse agro-ecologies ranging from highly drought-prone north-western parts of India to relatively favourable southern regions of country. Availability of diverse cultivars is essential in order to meet necessity of regional adaptation to various climatic stresses and to fulfil the need of differential preference of various phenotypic traits by farmers of different areas (Yadav et al., 2012). Genetic diversity is also very vital in disease management, especially downy mildew, which is the most destructive disease of genetically homogeneous hybrids of pearl millet.

Pearl millet hybrid breeding is one of the most successful programmes in India (Gill, 1991; Dave, 1987; Harinarayana et al., 1999; Yadav and Rai, 2013). Large number of hybrids, developed by both public and private sector organizations, have been widely adopted by Indian farmers (Yadav et al., 2012). However, little information exists on magnitude of diversity in commercial hybrids, though some information is available on extent of genetic diversity in landraces (Vyas and Pokhriyal, 1985; Appa Rao et al., 1986), inbreds (Virk, 1988) and experimental crosses (Pethani and Dave, 1992; Khairwal and Singh, 1999). Therefore, current study attempted to quantify the degree of diversity in commercial hybrids of pearl millet. The relationship among various phenotypic traits and between grain yield and quality traits was also examined.

\section{Materials and Methods}

The experimental material consisted of 122 hybrids including 21 hybrids from nine public sector research

*Author for Correspondence: Email-opyadav21@yahoo.com 
organizations and 101 hybrids from 33 seed companies. While the hybrids from public sector were all released and notified, those from the private sector consisted of both released and notified for general cultivation as well as those marketed as truthfully labelled seed. The seed of the hybrids used in this experiment were obtained from respective institutes and organizations that developed those hybrids.

Hybrids were evaluated at the All India Coordinated Pearl Millet Improvement Project (AICPMIP), Jodhpur, Rajasthan; CCS Haryana Agricultural University, Hisar, Haryana; and the International Crops Research Institute for the Semi-Arid Tropics (ICRISAT), Patancheru, Telangana. Each site represented one of the three megaenvironments of pearl millet production ecology: A1 zone was represented by Jodhpur, A zone by Hisar and B zone by Patancheru (Gupta et al., 2013). The soils were sandy, loamy and sandy loam at Jodhpur, Hisar and Patancheru, respectively.

At each site, hybrids were evaluated in three replications using alpha-lattice design in $4 \mathrm{~m}$ long 4-6 row plots during rainy season of 2012. The hybrids were sown in plots followed by thinning of seedlings within first two weeks of sowing to maintain a final spacing of $15 \mathrm{~cm}$ within row that were spaced $60 \mathrm{~cm}$ apart at Jodhpur and Hisar and $75 \mathrm{~cm}$ at Patancheru. The trials were grown under good management conditions to allow optimal expression of hybrids.

Data were recorded for grain yield, five phenotypic traits and two grain quality traits. Days to flowering were recorded on plot basis as number of days from sowing till time the stigma emerged in the main panicle of 50\% plants in a plot. Plant height and main panicle length were recorded at the time of maturity on five competitive plants in a plot. Data on plant stand and panicle number were used to calculate panicles per plant. At the time of maturity, the panicles were harvested and put in gunny bags for drying, rather than on ground, to avoid any contamination with dust. Grain yield was recorded on plot basis at Jodhpur and Patancheru and converted into $\mathrm{kg} / \mathrm{ha}$. Part of grain samples from these two locations were used to record 1000-grain weight and for analysis of $\mathrm{Fe}$ and $\mathrm{Zn}$ concentration using Inductively Coupled Plasma Optical Emission Spectroscopy (Wheal et al., 2011) at the Waite Analytical Services Laboratory, Australia.

Data recorded on all traits were subjected to analysis of variance at individual location and across locations.
Association of various traits with grain yield was studied using Pearson's correlation coefficients. Hybrids were grouped in clusters using five highly heritable phenotypic traits viz., days to flower, plant height, panicle length, panicles/plant and 1000-grain weight. Pooled data for each trait was used for calculating pair-wise genetic dissimilarity index following the method of Euclidean distance using Ward's minimum variance method (Ward, 1963).

\section{Results and Discussion}

\section{Magnitude of Variation}

The climatic conditions at three test locations varied considerably resulting in variable expression of all traits at different locations (Table 1). Diverse growing conditions resulting in differential expression of traits at three locations indicated that the results of this study may be applicable to a varied range of environments under which pearl millet is cultivated in various agroecologies of country.

The mean flowering time of hybrids at Patancheru was 45 days, which was 7-13 days lesser than the mean flowering time recorded at Jodhpur and Hisar (Table 1). This was due to shorter day length at Patancheru that resulted in early flowering as pearl millet is a short-day plant (Burton, 1983). This also resulted in shorter plant height $(189 \mathrm{~cm})$ at Patancheru than at other two locations. Both tillering and panicle length were also variable across test locations. Plant tillered most profusely at Patancheru followed by Hisar and Jodhpur. However, mean panicle length was maximum at Hisar $(26 \mathrm{~cm})$ and minimum at Patancheru $(23 \mathrm{~cm})$. The mean grain yield of hybrids ranged from $4880 \mathrm{~kg} / \mathrm{ha}$ at Jodhpur and $6110 \mathrm{~kg} / \mathrm{ha}$ at Patancheru.

Hybrids differed significantly for all traits at individual location and across locations (data not presented). Enormous variation was observed for flowering time from 42 to 58 days. Five hybrids

Table 1. Trait means in pearl millet evaluated at three locations during rainy season of 2012

\begin{tabular}{lrrc}
\hline Trait & Jodhpur & Hisar & Patancheru \\
\hline Time to flower (days) & 52.2 & 57.9 & 44.9 \\
Plant height (cm) & 253.6 & 242.1 & 188.6 \\
Panicles/plant (No.) & 1.61 & 1.92 & 2.13 \\
Panicle length (cm) & 24.1 & 26.2 & 23.0 \\
Grain yield (kg/ha) & 4880 & - & 6110 \\
1000-grain weight (g) & 10.3 & - & 13.0 \\
\hline - No data & & &
\end{tabular}


flowered within 45 days, while 30 hybrids (25\%) took 46-50 days for flowering (Fig. 1). Half of the hybrids flowered between 51 and 55 days and remaining hybrids (19) could flower beyond 55 days. Such a wide range in flowering time showed that current hybrids could cater to the need of highly drought-prone regions in north-western India requiring early maturing hybrids to escape terminal drought (Bidinger et al., 1987) and also of relatively more favourable areas where slightly longer duration helps in capturing additional moisture resources for crop (van Oosterom et al., 2003).

Large variability was also observed for tillering (1.14.4 panicles/plant) and seed size with 1000-grain weight ranging from 7.6 to $17.3 \mathrm{~g}$. High tillering hybrids get a strong preference by farmers of drought-prone areas in the states of Rajasthan, Gujarat and Haryana as tillering is a part of mechanism of adaptation to intermittent drought periods (van Oosterom et al., 2006; Yadav et al., 2011) that are of common occurrence during the crop season (Yadav et al., 2011). Most of the hybrids produced large grains with a 1000-grain weight of $>10 \mathrm{~g}$. This is a reflection of a high priority given in pearl millet breeding programme of the country for bold seeds which find favour with vast majority of farmers cultivating pearl millet. There was also a wide range in height $(185-268 \mathrm{~cm})$ and panicle length $(20-33 \mathrm{~cm})$ among hybrids.

Grain yield of hybrids varied more than two fold from 3.5 to $7.2 \mathrm{t} / \mathrm{ha}$. About $25 \%$ of hybrids yielded more than $6.0 \mathrm{t} / \mathrm{ha}$. Available environmental resources like soil type, water availability and input supply determine the crop productivity. The yielding ability of hybrids up to $7.2 \mathrm{t} / \mathrm{ha}$ demonstrated the potential productivity of present pearl millet hybrids. The realized grain yield at farmers' field during summer season in parts of Gujarat, Uttar Pradesh and Rajasthan is up to 5.5 t/ha which makes pearl millet a commercial rather than a subsistence crop.

Clustering of hybrids resulted in seven distinct clusters (Fig. 2) with considerable diversity within each cluster. The size of the individual clusters varied considerably. Two largest clusters contained 24-27 hybrids, while three clusters included 17-19 hybrids. Remaining two clusters had 8-9 hybrids. It was interesting to note that 14 of 20 maturing hybrids bred for drought prone environments from public sector clustered in Cluster 1, though the remaining six hybrids were spread in three clusters. The hybrids developed by different private companies were spread across seven different clusters that underlined very diverse nature of the individual hybrids bred by various organizations. Though this study assessed diversity of hybrids on the basis of phenotypic traits, there are reports (Nepolean et al., 2012; Gupta et al., 2015) of high molecular diversity among the parental lines that have been widely used by both public and private sector in developing most of the hybrids tested in this study.

Spread of 122 hybrids in 7 mega-clusters clearly indicated wide diversity in commercial hybrids of pearl millet highlighting the successful efforts of national programme of pearl millet improvement towards genetic diversification of hybrids. This might be the key reason that during last 25 years, there has been no downy mildew epidemic in India unlike those witnessed frequently before 1990. Otherwise, the downy mildew had become most important biotic constraint during 1970s and 1980s. A critical appraisal of the situation (Dave, 1987; Yadav and Rai, 2013) revealed that downy mildew epidemics in mid 1970s and 1980s were mainly due to lack of diversity in hybrids. During 1965-75, all hybrids were first based on Tift 23A and then on 5141A. Similarly, the same restorers were also repeatedly used in combinations with different male-sterile lines. Three restorers (J 104, K 560 and K 559) were male parents of nine commercial hybrids. Similarly two restorers (H90/4-5 and H77/833-2) were utilized in developing five hybrids. These facts indicate that outbreaks of downy mildew were due to a narrow genetic base among seed parents and restorers (Yadav et al., 1993; Yadav, 1996).

Thus investment made in genetic diversification of pearl millet hybrids by Indian programme has paid enormous dividends not only by containing the downy mildew but also by providing a wide range of choice to farmers to select hybrids that fulfil their requirements of local adaptation and other preferred phenotypic traits. This is the major reason of achieving higher growth in productivity of pearl millet as compared to that in wheat, rice, sorghum and maize (Yadav and Rai, 2013) during last 25 years. Use of diverse and downy mildew resistant genetic material in the development of both seed and restorer parents would be a continual necessity to further promote the genetic diversity in hybrid breeding.

The Fe density among the hybrids varied from 31 to $61 \mathrm{mg} / \mathrm{kg}$ with mean concentration of $45 \mathrm{~m} / \mathrm{kg}$. On the other hand, the $\mathrm{Zn}$ density ranged from 32 to 52 $\mathrm{mg} / \mathrm{kg}$ with mean $\mathrm{Zn}$ concentration of hybrids being 41 $\mathrm{mg} / \mathrm{kg}$. The wide range in the concentration of both Fe 


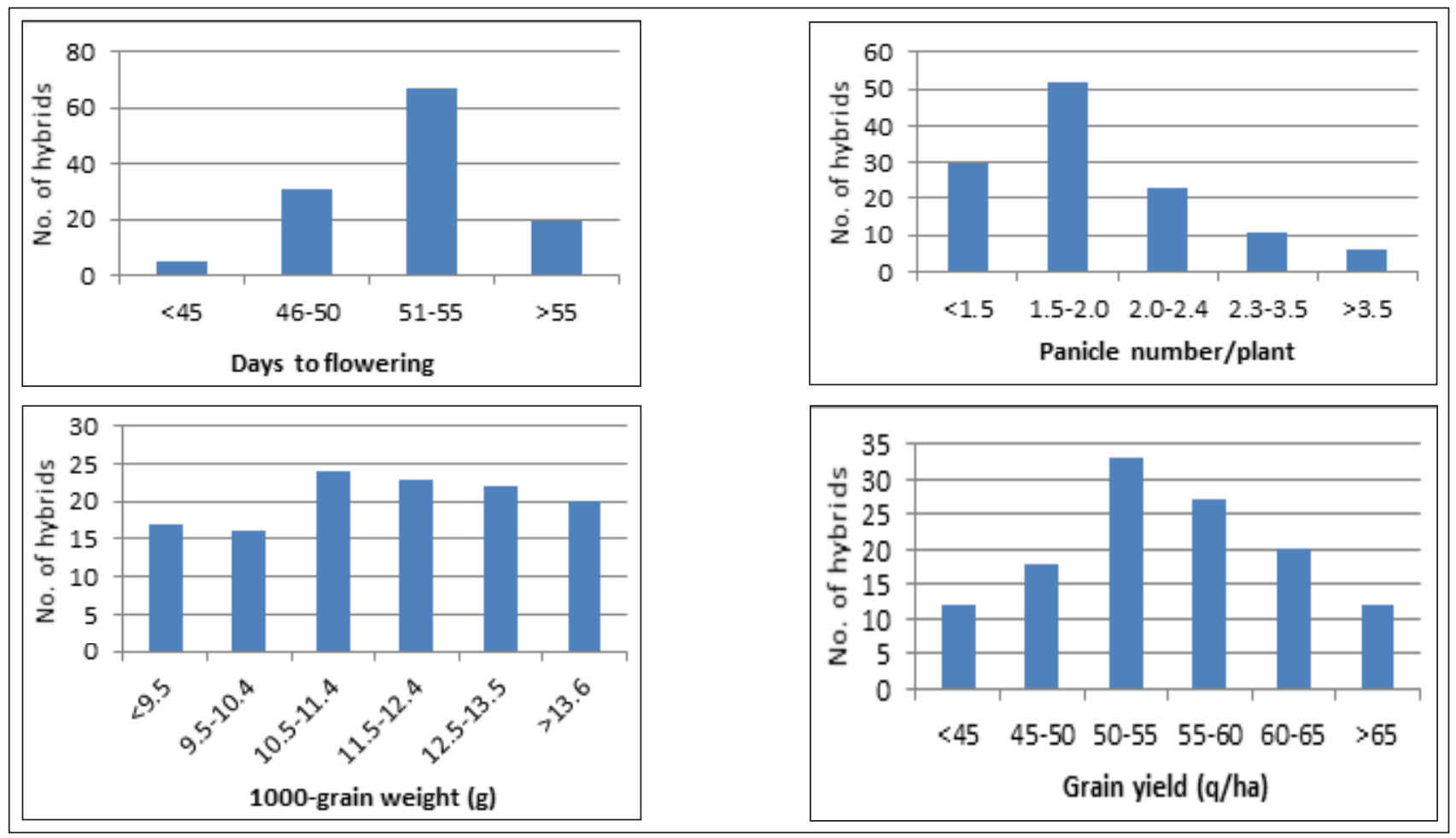

Fig. 1. Frequency distribution of pearl millet hybrids in different classes for grain yield and three phenotypic traits

and $\mathrm{Zn}$ among pearl millet hybrids showed that there existed good choice in commercial cultivars for selecting high yielding hybrids coupled with high concentration of these micronutrients.

\section{Association among Traits}

Phenology, tillering and plant height had significant influence on grain yield of hybrids. The correlation between grain yield and days to flowering was significant and positive (Table 2), though lateness could explain only $12 \%$ of variation in grain yield. This showed that late flowering hybrids tended to yield higher which was expected since moisture was not a limiting factor during evaluations. These results, however, need to be interpreted with slight caution as extending duration beyond a limit (say 85 days) will increase the chances of terminal drought in rainfed crop like pearl millet.

Taller hybrids gave higher grain yield as indicated by highly significant positive association between height and grain yield (Table 2). It is well established in cereals that greater height results in greater biomass that has direct influence on grain yield (Austin et al., 1993). Tillering in hybrids was strongly associated with their duration, tallness and panicle length. Hybrids with lesser duration and shorter height produced more tillers as indicated by significant negative association of panicles per plant with days to flowering and plant height. Tillering decreased with the increase in panicle length as showed by significant negative correlation between panicle length and panicle number per plant. Such compensation in yield components is a part of yield formation process (Austin et al., 1993) and has direct relevance in prioritizing the traits during selection and cultivar development.

The correlation of grain yield with both Fe and $\mathrm{Zn}$ concentration was non-significant (Table 3) suggesting that both these micronutrients can be improved without significantly compromising on grain yield. A highly significant and positive correlation was observed between grain $\mathrm{Fe}$ and $\mathrm{Zn}$ densities of hybrids which is in conformity with earlier results obtained with a wide range of diverse material (Velu et al., 2007, 2008; Rai et al., 2012). Grain size had moderate to weak but positive correlation with $\mathrm{Fe}$ and $\mathrm{Zn}$ contents and no adverse effect on grain yield. These results clearly indicated that it should be possible to develop largeseeded hybrids with higher $\mathrm{Fe}$ and $\mathrm{Zn}$ concentration without compromising their yielding ability.

The results of this study have clearly indicated that there is enough diversity in commercial hybrids of pearl millet to cater to the need of diverse agro-ecology of 


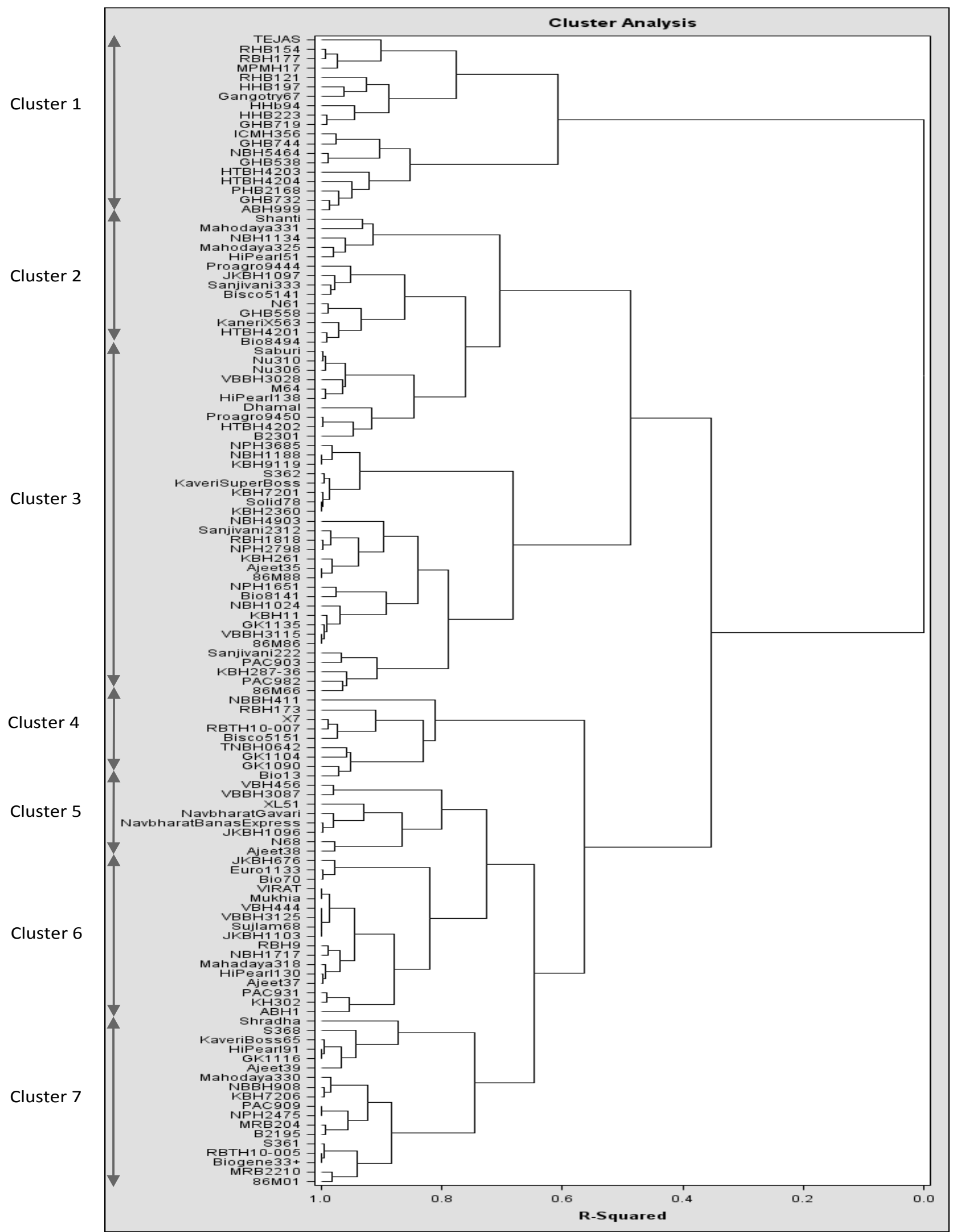

Fig. 2. Clustering of 122 hybrids of pearl millet following the method of Euclidean distance 
Table 2. Correlation coefficients among four phenotypic traits and grain yield in 122 hybrids based on mean at three locations

\begin{tabular}{|c|c|c|c|c|c|}
\hline Trait & Days to flowering & Plant height & Panicles/plant & Panicle length & Grain yield \\
\hline Days to flowering & 1.00 & & & & \\
\hline Plant height & $0.72 * *$ & 1.00 & & & \\
\hline Panicles/plant & $-0.57 * *$ & $-0.46 * *$ & 1.00 & & \\
\hline Panicle length & 0.16 & $0.27^{*}$ & $-0.42 * *$ & 1.00 & \\
\hline Grain yield & $0.36 * *$ & $0.34 * *$ & $-0.28^{*}$ & 0.04 & 1.00 \\
\hline
\end{tabular}

*,** significant at probability levels of $5 \%$ and $1 \%$, respectively

Table 3. Correlation coefficients among grain yield and three seed traits in $\mathbf{1 2 2}$ hybrids based on mean at three locations

\begin{tabular}{|c|c|c|c|c|}
\hline Trait & 1000 seed weight & Fe concentration & Zn concentration & Grain yield \\
\hline 1000- seed weight & 1.00 & & & \\
\hline Fe content & 0.18 & 1.00 & & \\
\hline Zn content & $0.31 * *$ & $0.70 * *$ & 1.00 & \\
\hline Grain yield & 0.12 & -0.09 & -0.03 & 1.00 \\
\hline
\end{tabular}

*, ** significant at probability level of $1 \%$

crop. Cultivation of a large number of diverse hybrids has also helped in containing the downy mildew that was threatening hybrid technology per se in pearl millet a few decades back. Availability of this diversity would also play a critical role in adaptation to situation emerging out of climate change.

\section{References}

Appa Rao S, MH Mengesha, KL Vyas and C Rajagopal Reddy (1986) Evaluation of pearl millet from Rajasthan. Indian J. Agril. Sci. 56: 4-9.

Austin RB, MA Ford, C Morgan and D Yeoman (1993) Old and modern wheat cultivars compared on the Broadbalk wheat experiment. Eur. J. Agron. 2: 141-7.

Basavaraj G, P Parthasarathy Rao, S Bhagavatula and W Ahmed (2010) Availability and utilization of pearl millet in India. J. SAT Agric. Res. 8: 1-6.

Bidinger FR, V Mahalakshmi and GDP Rao (1987) Assessment of drought resistance in pearl millet [Pennisetum americanum (L.) Leeke]. I. Factors affecting yield under stress. Aust. J. Agric. Res. 38: 37-48.

Burton GW (1983) Breeding pearl millet. Plant Breed. Rev. 1: $162-82$.

Dave HR (1987) Pearl millet hybrids. In: Proceedings of the International Pearl Millet Workshop, 7-11 April 1986. ICRISAT Center, Patancheru, pp 121-126.

Gill KS (1991) Pearl millet and its improvement. Indian Council of Agricultural Research, New Delhi.

Gupta SK, A Rathore, OP Yadav, KN Rai, IS Khairwal, BS Rajpurohit and RR Das (2013) Identifying mega-environments and essential test locations for pearl millet cultivar selection in India. Crop Sci. 53: 2444-53.

Gupta SK, T Nepolean, MS Sankar, A Rathore, RR Das, KN Rai and CT Hash (2015) Patterns of molecular diversity in currenand previously developed hybrid parent of pearl millet [Pennisetum glaucum (L.) R. Br.]. American J. Plant Sci. 6: 1697-1712.
Harinarayana G, K Anand Kumar and DJ Andrews (1999) Pearl millet in global agriculture. In: IS Khairwal, KN Rai, DJ Andrews and G Harinarayana (eds.), Pearl millet breeding. Oxford and IBH Publishing Co. Pvt. Ltd., New Delhi, pp 479-506.

Khairwal IS and S Singh (1999) Quantitative and qualitative traits. In: IS Khairwal, KN Rai, DJ Andrews and G Harinarayana (eds.), Pearl millet breeding. Oxford and IBH Publishing Co. Pvt. Ltd., New Delhi, pp 119-55.

Nepolean T, SK Gupta, SL Dwivedi, R Bhattacharjee, KN Rai and CT Hash (2012) Genetic diversity in maintainer and restorer lines of pearl millet. Crop Sci. 52: 2555-2563.

Pethani KV and HR Dave (1992) Heterosis for grain yield in pearl millet (Pennisetum typhoides (B) S\&H). Indian J. Genet. Plant Breed. 52: 45-49.

Rai KN, M Govindaraj and AS Rao (2012) Genetic enhancement of grain iron and zinc content in pearl millet. Quality Assur. Safety Crops Food 4: 119-125.

Rai KN, CLL Gowda, BVS Reddy and S Sehgal (2008) The potential of sorghum and pearl millet in alternative and health food uses. Comp. Rev. Food. Sci. Food. Saf. 7: 340-352.

Van Oosterom EJ, FR Bidinger and RE Weltzien (2003) A yield architecture framework to explain adaptation of pearl millet to environmental stress. Field Crops Res. 80: 33-56.

Van Oosterom EJ, E Weltzien, OP Yadav and FR Bidinger (2006) Grain yield components of pearl millet under optimum conditions can be used to identify germplasm with adaptation to arid zones. Field Crops Res. 96: 407-421.

Velu G, KN Rai, V Muralidharan, VN Kulkarni, T Longvah and TS Raveendran (2007) Prospects of breeding biofortified pearl millet with high grain iron and zinc contents. Plant Breed. 126: 182-185.

Velu G, KN Rai, KL Sahrawat and K Sumalini (2008) Variability for grain iron and zinc contents in pearl millet. SAT J. Agric. Res. 6: 1-4.

Virk DS (1988) Biometrical analysis in pearl millet-a review. Crop Improv. 15: 1-29. 
Vyas KL and SC Pokhriyal (1985) Combining ability of landraces of pearl millet from Rajasthan. Indian J. Genet. 45: $247-254$.

Ward JH (1963) Hierarchical grouping to optimize an objective function. J. American Stat. Assoc. 58: 236-244.

Wheal MS, TO Fowles and LT Palmer (2011) A cost-effective acid digestion method using closed polypropylene tubes for inductively coupled plasma optical emission spectrometry (ICP-OES) analysis of plant essential elements. Analy. Methods 3: 2854-2863.

Yadav OP (1996) Downy mildew incidence of pearl millet hybrids with different male-sterility inducing cytoplasms. Theor. Appl. Genet. 92: 278-280.

Yadav OP, VK Manga and GK Gupta (1993) Influence of A1 cytoplasmic substitution on downy mildew incidence in pearl millet. Theor. Appl. Genet. 87: 558-560.
Yadav OP and KN Rai (2013) Genetic improvement of pearl millet in India. Agric. Res. 2: 275-292.

Yadav OP, KN Rai, IS Khairwal, BS Rajpurohit and RS Mahala (2011) Breeding pearl millet for arid zone of north-western India: constraints, opportunities and approaches. All India Coordinated Pearl Millet Improvement Project, Jodhpur, India, $28 \mathrm{p}$.

Yadav OP, KN Rai, BS Rajpurohit, CT Hash, RS Mahala, SK Gupta, HS Shetty, HR Bishnoi, MS Rathore, A Kumar, S Sehgal and KL Raghvani (2012) Twenty-five years of pearl millet improvement in India. All India Coordinated Pearl Millet Improvement Project, Jodhpur, India, 122 p. 